\title{
Research on the Motive Mechanism of Teaching Development in Colleges and Universities
}

\author{
Tao Huang \\ college of Physical Education, Taishan University, 271000
}

\begin{abstract}
If you want to promote the deeper implementation of higher education reform, you need to realize the importance of improving teachers' teaching ability and teaching level, and through the implementation of high-quality teaching activities, lay a solid foundation for the school's future long-term development. Therefore, the effective establishment of motivation mechanism can effectively promote the overall development of teachers, and can also ensure the smooth development of various tasks in the school. This article starts with the importance of the construction of the motivation mechanism for teaching development, looking for specific ways to effectively improve colleges and universities combined with the actual situation to improve the teacher development motivation system, hoping to provide some reference value for other teachers.
\end{abstract}

Keywords: Teacher development; education reform; colleges and universities; motivation mechanism research

The continuous in-depth implementation of the reform work in the field of higher education has enabled many colleges and universities to continue to build teaching development centers, hoping to provide teachers with more channels to promote their teaching ability, teaching experience and teaching level, so as to establish high literacy In the process of building a team of teachers, it will promote the school's future great development. Many teachers are often restricted by work pressure, assessment mechanism, occupational sense of belonging, and job title evaluation when participating in work activities. Restricting their development motivation during teaching makes it difficult for teachers to understand teaching work and career Under the current situation of balance, it is difficult to obtain high-quality improvement in work quality. This requires the school to actively build a motivation mechanism that promotes better teacher development, so that teachers can mobilize their work enthusiasm and ensure better teaching activities.

\section{The importance of the construction of motivation mechanism for teaching development}

\subsection{Intrinsic motivation}

Teaching is the origin of educational work, and it is also an important driving force for students' better development. Therefore, the improvement of the motivation mechanism of teaching development can promote the teacher's internal motivation, so that the teacher's education work always revolves around cultivating high-quality outstanding talents. In order to improve the teaching ability of teachers and make them an inexhaustible motive force to ensure that teachers are more like work, schools need to provide teachers with a learning platform so that teachers can implement their own tasks through the research of new educational theories To cultivate high-quality talents that meet the needs of social development. Therefore, when teaching activities, teachers need to use students' learning effectiveness as an internal driving force to promote their own development. Through the improvement of teaching methods and the introduction of high-quality classroom situations, the limitations of traditional teaching concepts are broken through so that students can be guided by teachers To better complete the learning of knowledge. This can not only promote students' enthusiasm for

Copyright (C) 2020 Tao Huang

doi: $10.18282 /$ le.v9i5.1227

This is an open-access article distributed under the terms of the Creative Commons Attribution Non-Commercial License

(http://creativecommons.org/licenses/by-nc/4.0/), which permits unrestricted non-commercial use, distribution, and reproduction in any medium, provided the original work is properly cited. 
learning, but also enable teachers to develop better in the process of effectively training students' teaching abilities.

\subsection{External power}

In order to improve the teaching level and ability of teachers, many colleges and universities have established a teaching evaluation system according to the actual situation of the school, hoping that teachers can ensure the successful completion of various tasks under the standardization and guidance of the system. The teaching evaluation system is directly related to the status of teachers, the selection of professional titles, and various honors. Therefore, as an external driving force to promote the development of teachers' teaching, teachers can be encouraged to constantly based on their own evaluation results in the process of maintaining a high teaching enthusiasm. Design a self-improvement plan in a targeted manner, and enrich yourself through continuous learning to ensure the high-quality completion of teaching work.

\section{Specific ways for colleges and universities to perfect the motivation mechanism of teaching development}

\subsection{Improve the security system and enhance the internal driving force}

The promotion of teaching development is an organic process of integration of various links. When establishing and perfecting the teaching development motivation mechanism, colleges and universities need to provide teachers with better quality services, and at the same time, through the improvement of the guarantee system, to ensure that teachers' teaching ability can be smoothly improved.

On the one hand, the school needs to establish a more standardized teacher training mechanism to provide a strong guarantee for teachers' teaching development, and to improve the training methods and content for teachers' needs, so as to ensure the smooth progress of training and achieve the improvement of teachers' teaching ability purpose.

On the other hand, the school needs to perfect the systems such as the "Implementation Plan of the Teachers' Leading Plan" and "Implementation Plan of the Teachers' Leading Plan" through the understanding of teachers' teaching experience and teaching level, and increase the visiting system and teaching salon system accordingly. When teachers participate in training activities, they can learn and accumulate professional knowledge and teaching experience more comprehensively. This not only better promotes the level of teachers' teaching development, but also makes the school's elaborate guarantee system make the internal power an inexhaustible power to promote teaching development.

\subsection{Improve the evaluation system and enhance the role of external and internal motivation}

First, in order to make the motivation mechanism better promote the teaching development of teachers, schools need to use students as the center of teaching evaluation when constructing and perfecting the teaching evaluation system. The specific process is that the school improves the teacher evaluation system in a targeted manner according to the students' evaluation and opinions on the teachers' teaching activities, so that the teachers can make changes to the teaching plan through the students' real-time feedback. In this way, teachers can meet the learning needs of students while accomplishing teaching tasks more objectively, and then under the promotion of the evaluation system, external motivation becomes an important support to promote the development of teaching.

Second, in the establishment of evaluation institutions, colleges and universities need to form a professional teaching evaluation team, composed of school administrators and teachers and students. This not only makes the teaching evaluation results more comprehensive, but also enables teachers to objectively recognize their own shortcomings, and then promote the better development of teaching work while continuously improving themselves.

\section{Conclusion}

In a word, in order to promote more comprehensive development of teachers, colleges and universities need to take into account the actual situation of the school, through in-depth research on the motivation mechanism of teaching development, according to the teacher's work attitude, teaching ability, teaching experience and professional status Improve and construct the power mechanism sexually. This can not only create a platform for teachers to improve themselves, but also enable teachers to improve themselves through continuous learning and accumulation in the process 
of enhancing work enthusiasm, thereby promoting the completion of teaching activities and becoming a vigorous future for colleges and universities. The power of development.

\section{References}

1. Bai Yiru, Bao Weibin, Wang Youqi. An Analysis of the Path of "Huang Danian Spirit" Integrating into the Construction of Teaching and Scientific Research Teams in Colleges and Universities_-Taking Ningxia University's Environmental Science Professional Team Construction as an Example[J]. Education Teaching Forum, 2020(20): 1 -2.

2. Shen Hongwei. Educational narrative research on micro-classes promoting the cooperative development of English teachers in colleges and universities__ Based on the thinking of the 10th "Foreign Teachers' Cup" National College Foreign Language Teaching Contest[J]. English Teachers, 2020,20(08):120 -122.

3. Kang Shining. A Comparative Study of the Construction of Teacher Development Centers in Chinese and American Universities_- Taking the Learning and Teaching Research Center of the University of Michigan as an example[J]. Modern Education Technology, 2019,29(11):60-66. 